\title{
Open-Loop Control Design of Shape Memory Alloys and Polymers through Tapping Motion
}

\author{
Victoria Oguntosin * \\ * Corre spondence: De partment of Electrical \& Information Engineering, Covenant University, KM10, \\ Idiroko Road, Ota, Ogun State, Zip Code:112233, Nigeria, \\ victoria.oguntosin@covenantuniversity.edu.ng; Te1.:+234-901-810-7052
}

\begin{abstract}
Shape Memory Alloys and Polymers are a class of smart materials that remember a pretrained shape or form when exposed to an appropriate temperature. In this work, Shape Memory Alloys consisting of wires, 1-w ay springs, and 2-w ay springs are described; an open-loop control of Shape Memory Alloys and Polymers is also implemented. Since the amount of electric current that flows through a wire is directly proportional to temperature, control of the electric circuit is used for open-loop temperature control. The designed smart control is applied to rotate a lever mechanism through the conversion of the linear motion of the Shape Memory Alloy into the rotational motion of the lever through the tapping of a piezoelectric transducer to deliver the openloop control. When the piezo transducer is deformed by mechanical stress via tapping, striking or any other mechanical stimulus, it produces an electrical signal which when sent to the microelectronic circuit activates the SMA. The implemented system can be applied in robotic systems and autonomous applications.
\end{abstract}

Keywords: shape memory alloys; shape memory polymers; open-loop control

\section{Introduction}

Shape Memory alloys are able to change their shape when the temperature changes [1]. A length of coiled 'memory wire' is straightened when put into hot water. The wire is being heated directly by contact with something hot. Since a Shape Memory alloy has a relatively high electrical resistance, it can also be made hot by passing an electrical current through it. This shape memory effect has been used in robots, in which the change in shape of a smart wire when a current is passed through it can be used to create movement in a robot arm [2]. When a shape memory wire is used like this it is also called muscle wire.

Shape Memory Alloys are made from Nickel and Titanium and are otherwise called Nitinol [3]. Equal amounts of nickel and titanium are combined and melted in an electric furnace at $1300^{\circ} \mathrm{C}$. The process is carried out in a vacuum and any contamination by other material is strictly avoided. The melt is then cast into small ingots. The ingots are rolled into rod, bar or sheet form. If wire is required, the bar stock is further drawn down to diameter through very hard dies of decreasing diameter. Finally, the wireis given its memory by carefully controlled heat treatment and 'conditioning'. This process is carried out continuously [4]. Training a shape memory alloy involves a complex process of treatment over a number of cycles in which it is deformed, heated and cooled [5]. After manufacture. nitinol wire exists in two'states' (phases) dependent on temperature:

- Low temperature state in which the material has a martensite crystal structure ('relaxed', extended condition).

- High temperature state in which the material has an austenite crystal structure ('remembered', shortened condition).

The change from one state or phase to the other, caused by temperature change, is responsible for the changes in length of the wire. The behaviour of the wire can be represented on a graph in Figure 1 showing length against temperature change [6]. 


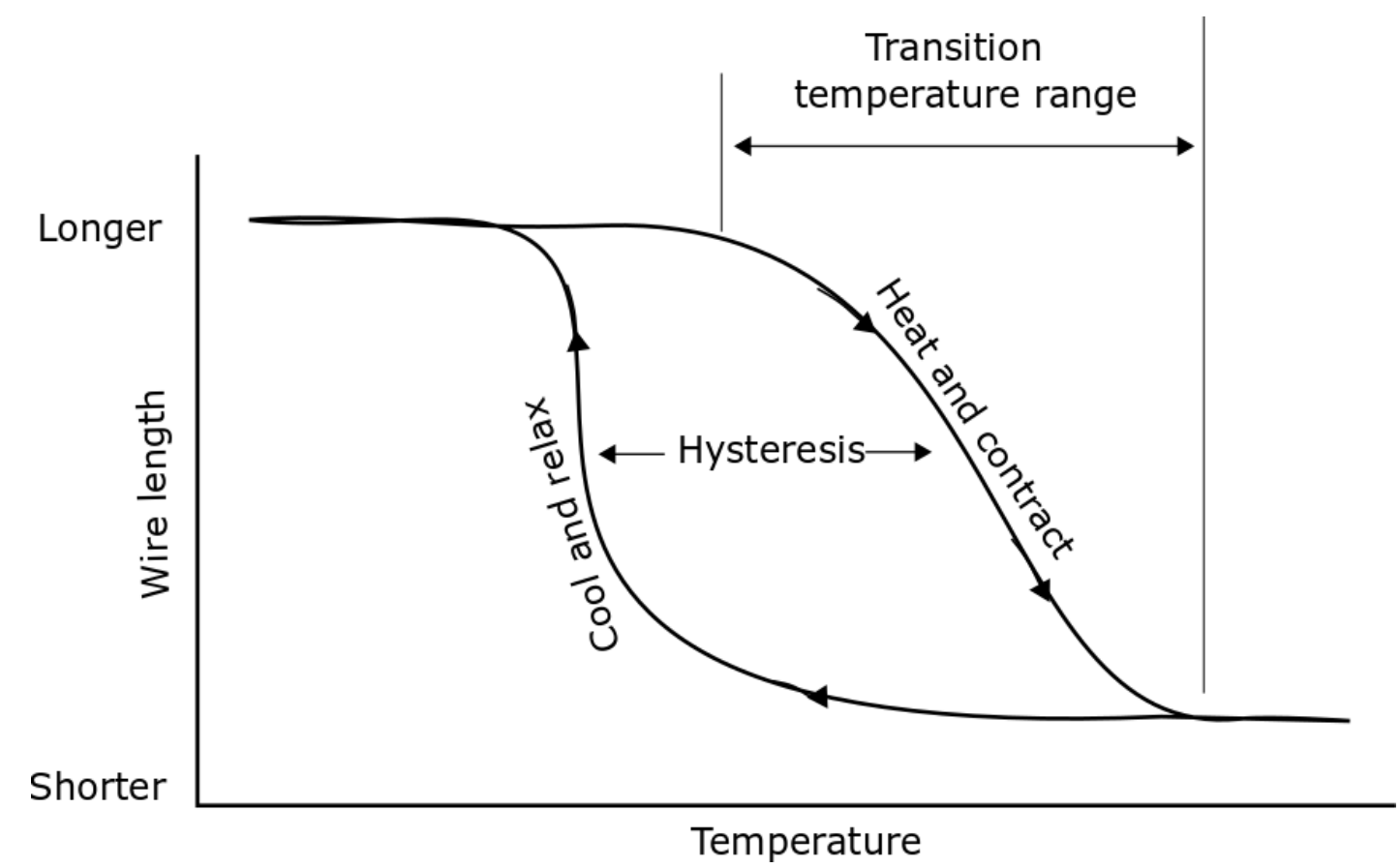

Figure 1. A Shape Memory Alloy contracts when temperature is increased and relaxes so that it can be formed into any shape when cooled.

When the wire is heated or cooled, the changes of state or phase are not immediate. At $68^{\circ} \mathrm{C}$ the high temperature phase begins and ends at $82^{\circ} \mathrm{C}$. A figure of $70^{\circ} \mathrm{C}$ is normally specified for convenience as the effective transition temperature. On cooling down, the low temperature phase begins at $52^{\circ} \mathrm{C}$ and ends at $42^{\circ} \mathrm{C}$. This temperature range differs considerably from the first and shows up on the graph as a hysteresis curve. Hysteresis is the retardation or lagging of an effect behind the cause of the effect or the difference between the higher transition temperature and the relaxation temperature [7].

These hysteresis characteristics become important when very rapid responses are required e.g., the wire can be heated rapidly with a large current which may then be reduced to maintain it in the shortened condition, if rapid relaxation is required, an active method of cooling such as moving air or immersion in a liquid can be used.

\section{Experiments}

In this section, experiments were conducted to describe the characteristics of shape memory alloys such as shape memory springs and wires, two-way shape memory alloys, shape memory polymers (SMP) and superelastic alloys.

\subsection{Shape Memory Wires}

At normal room temperature, a shape memory wire made from nitinol has to be stretched with a bias force of $0.3 \mathrm{~N}$. When heated to the transition temperature of between $70^{\circ}-80^{\circ} \mathrm{C}$, the wire shortens about $5 \%$ in length and will exert a pulling force of $1.5 \mathrm{~N}$. SMA wires not only contract when heated but can be trained to a specific shape or form so that when heated, they morph to a form but when cooled, they can exist in a different shape or form.

The speed at which the wire shortens when it reaches the transition temperature is about 0.1 seconds. It takes longer to relax or stretch back to its longer length - about 1 second. When heated, the wire actually starts changing length at $68^{\circ} \mathrm{C}$ and finishes at $78^{\circ} \mathrm{C}$. When it cools, the stretching or relaxation does not take place until it has reached $52^{\circ} \mathrm{C}$ as a result of hysteresis. 
The supply needed to heat the wire can be determined using Ohm's Law. This states the relationship between voltage $(V)$, current $(I)$ and resistance $(R)$ is given by $V=I R$. The voltage needed to pass the maximum safe current of $180 \mathrm{~mA}$ through a $10 \mathrm{~cm}$ length of wire with a diameter of $100 \mu \mathrm{m}$ is calculated as:

$$
\begin{gathered}
R=150 \Omega \mathrm{m}^{-1}=1.50 \Omega \mathrm{cm}^{-1}=15 \Omega 10 \mathrm{~cm}^{-1} \\
I=180 \mathrm{~mA}=0.18 \mathrm{~A} \\
V=I R=0.18 \mathrm{~A} \times 15 \Omega=2.7 \mathrm{~V}
\end{gathered}
$$

The pulling force of a Nitinol wire cannot be increased by supplying current beyond the recommended limit. However, two or more wires can be connected in parallel to a voltage source. Two wires in parallel will give double the pulling force but has to be supplied with double the current required to heat a single wire up. Figure $2 \mathrm{a}$ show s a nitinol wire of $0.5 \mathrm{~mm}$ in diameter and length of $155 \mathrm{~mm}$, when heated with a 12V, 1A DC supply, the wirestraightens up and contracts as shown in Figure $2 \mathrm{~b}$. The wire has to be continuously supplied with current in order to maintain its straightened and contracted form.

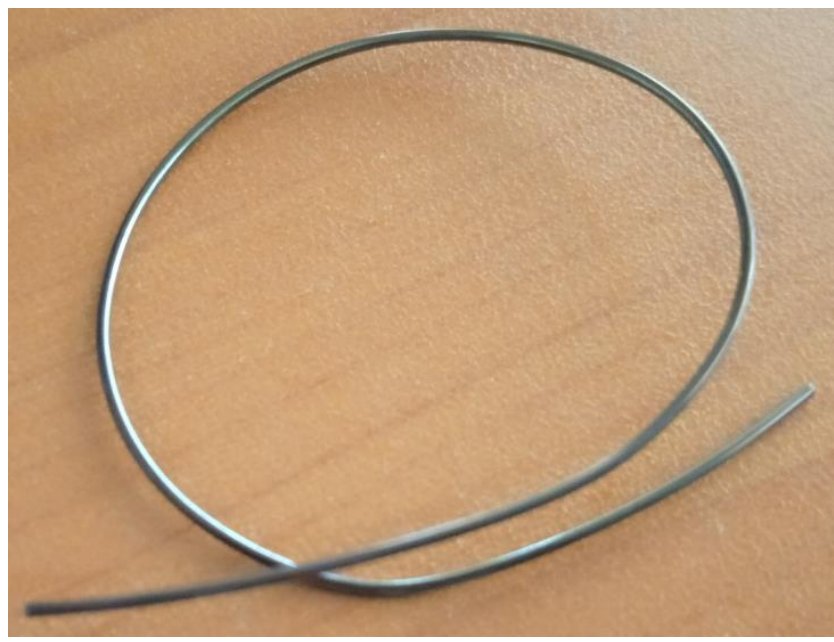

(a)

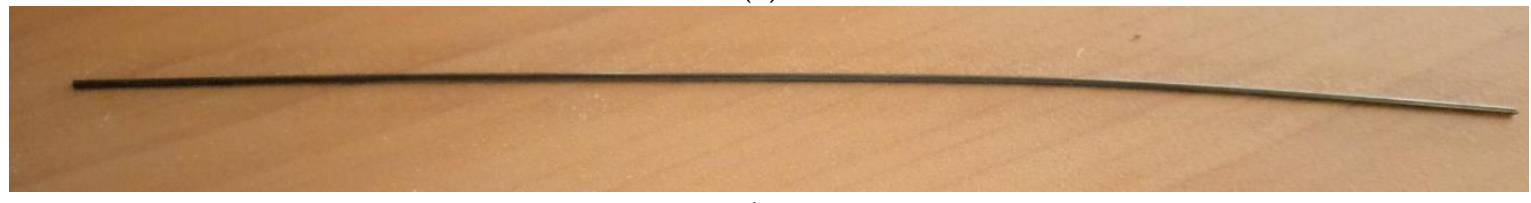

(b)

Figure 2. (a) A Nitinol wire can be formed or twisted into any shape when cool; (b) A Nitinol wire straightens up to a length of $155 \mathrm{~mm}$ and contracts when hea ted up. The electric current needs to be continuously supplied for the wire to remain straightened.

\subsection{Shape Memory Springs}

Similar to Shape Memory wires, Shape Memory Springs exists in two different forms. Form A is the 'remembered' form and is stable at higher temperatures; form B is more stable at lower temperatures. If the spring in form B is heated, it changes to form $\mathrm{A}$ and the spring becomes shorter. The reason for the change in length is due to the way the atoms are arranged. When the wire changes from form $\mathrm{B}$ to form $\mathrm{A}$, the atoms rearrange and the spring becomes shorter and thicker. The temperature at which this happens is called the transition temperature. SMA springs can ex ert quite substantial forces over a considerable distance. The smart spring used in this w ork has been trained during manufacture so that it contracts when heated. If a current of about 1A D.C. is passed through the spring, it contracts (Figure 3c); when the current is switched off, it is still in its contracted form and requires a restoring force to pull the spring because this is a one-way spring (Figure $3 b$ ). The original frorm of the spring is shown in Figure 3a before its first contraction cycle. 


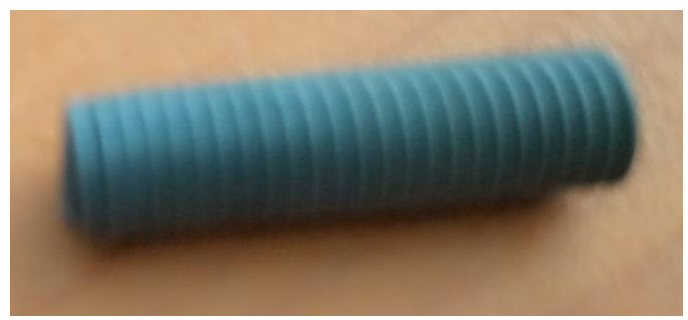

(a)

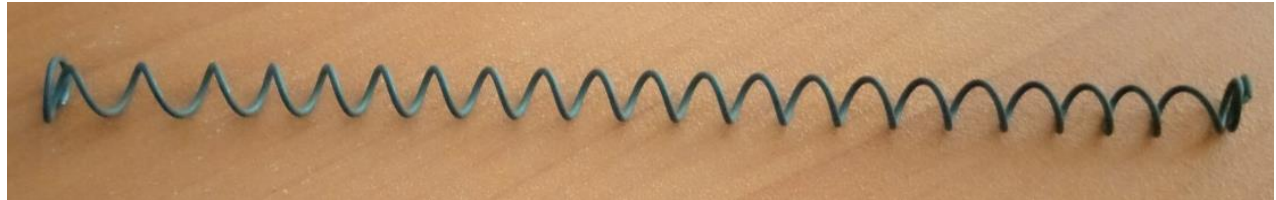

(b)

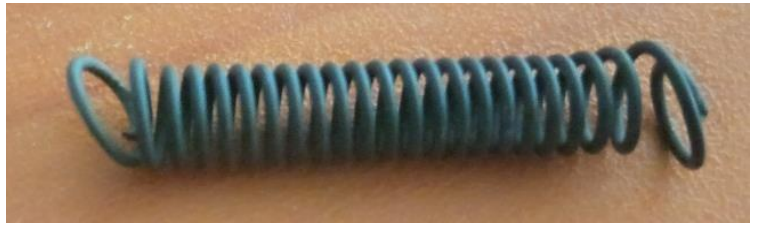

(c)

Figure 3. (a) A Sha pe Memory Spring in its fully contracted form of lenth $20 \mathrm{~mm}$ (Form A) before the first contraction cycle; (b) A Shape Memory Spring in its relaxed form (Form B) after it is stretched out to $150 \mathrm{~mm}$ by an external mechanical force; (c) A Shape Memory Spring in its contracted form of length 35mm (Form A) after multiple contraction cycles. The SMA spring does not return to its fully contracted form (Fig 3a) after multiple contraction cycles.

\subsection{Two-way Shape Memory alloy}

Different types of alloy behave in different ways. A two-w ay alloy changes its shapeboth when it is heated (Figure 4b) and when it is cooled (Figure 4a). However, the shape memory wire is made of a one-w ay alloy, getting shorter when it is heated, but rem aining the samelength when it is cooled. To get back to the original length, it needs to be pulled with a restoring force.

During manufacture, two-way SMA springs have been 'trained' so that they are closed when they are cold and open when they are heated [8]. The spring show s hysteresis behaviour, since the temperature at which it changes from form B to form $A$ is higher than the temperature it changes from form A to form B. The hysteresis behaviour is a very useful behaviour if a SMA is to be used in a thermostat, since these are designed so that they do not switch on and off at the same temperature. When this happens, the spring would rapidly switch on and off as the temperature goes slightly above and below the temperature setting which results in an unstablebang-bang control.

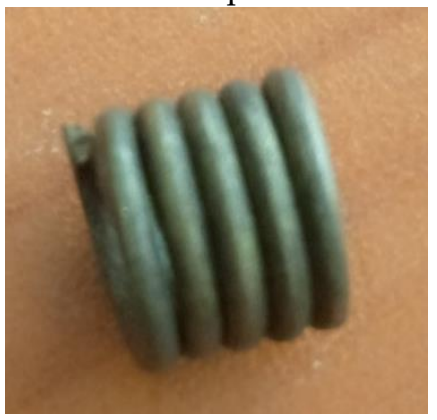

(a)

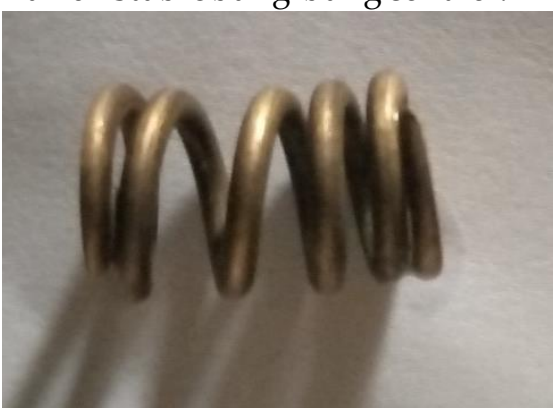

(b)

Figure 4. (a) A 2-way SMA spring is trained to be in its normally closed form of length $10 \mathrm{~mm}$ when cool; (b) A 2-way SMA spring is in its expanded form when heated by an electric current or high temperature.

\subsection{Shape Memory Polymer (SMP)}


When heated, Shape Memory Polymer (SMP) will temporarily soften. It can then be reshaped and will harden in seconds, maintaining the new configuration (Figure 5c). When reheated, Structural Repair Patch will return to its original cured shape (Figure 5a). SMP is a fiber-reinforced composite that uses Veriflex ${ }^{\circledR}$, as the matrix [9]. This allow s Structural Repair Patch to easily change shape above its activation temperature. At lower temperatures, the material maintains high strength and high stiffness.

Applications of SMP includes rapid manufacturing, lightweight, deployable structures, composite repair patching and adaptable reinforcement. The unique features and benefits of the SMP includes strengthening fabric reinforcement, ability to deform and recover shape repeatedly, ability to transform from rigid composite to soft elastomer, up to $80 \%$ elongation in elastic state, durability, machinability [10].

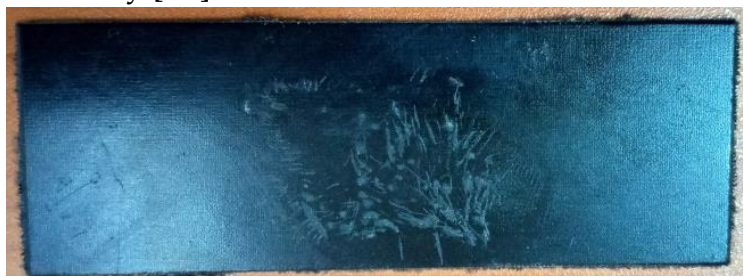

(a)

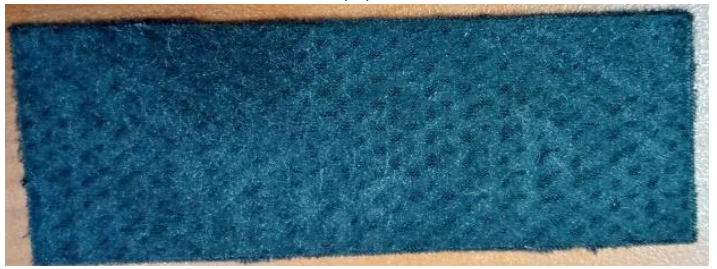

(b)

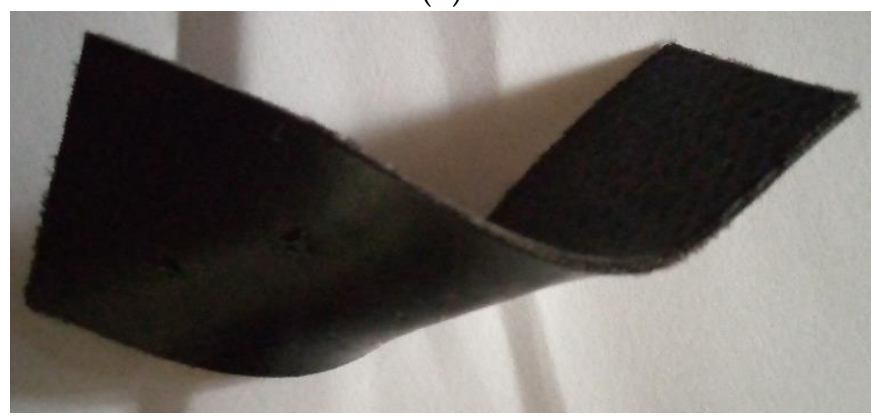

(c)

Figure 5. (a) The front of a Shape Memory Polymer in its original cured shape and at a low temperature, it has high strength and stiffness, when reheated, it returns to this original cure d shape; (b) the back panel; (c) A Shape Memory Polymer at a high temperature, it has been reshaped and maintains its new configuration. The strip of SMP composite has been warmed, twisted into a new shape and left to cool, when warmed again, it reverts to its original shape.

\subsection{Superelastic Alloys}

Like the SMA alloys described earlier, superelastic alloys also have a 'memory'. When they are bent or stretched they return to their original shape, though they do not need to be heated to do this [11]. These are the alloys used in some spectacle frames; by making the bridge and sides from superelastic alloy, the frames can be bent or twisted without being permanently deformed [12]. Superelastic alloy is also used in the archwires in dental braces [13], which can be stretched, positioned and released, thus exerting a force on the teeth. In medicine, the alloy is widely used for making stents [14]. These are cylinders of wire mesh that are inserted into a hollow structure of the body to keep it open, for example, an artery, vein, urethra or trachea. Superelastic alloys also fi nd applications in bra underwires and mobile phone antennae.

Superelastic alloys are also made of nickel and titanium and can exist as a 'short' form (A) and a 'long' form (B). What is different about a superelastic alloy is that its transition temperature is below 
room temperature. If it is stretched it changes to the 'long' form (B) (Figure 6b). If the force is released, it reverts to the 'short' form (A) (Figure 6a), which is more stable at room temperature, and it does not need to be heated for it to recover its remembered shape. This is because when superelastic wire stretches, the atoms slide back into a new arrangement; when the force is released, the atoms slide back again, so that its original length is recovered, a phenomenon called superelasticity [15]. Because this is very different from true elasticity, superelasticity is also known as pseudoelasticity.

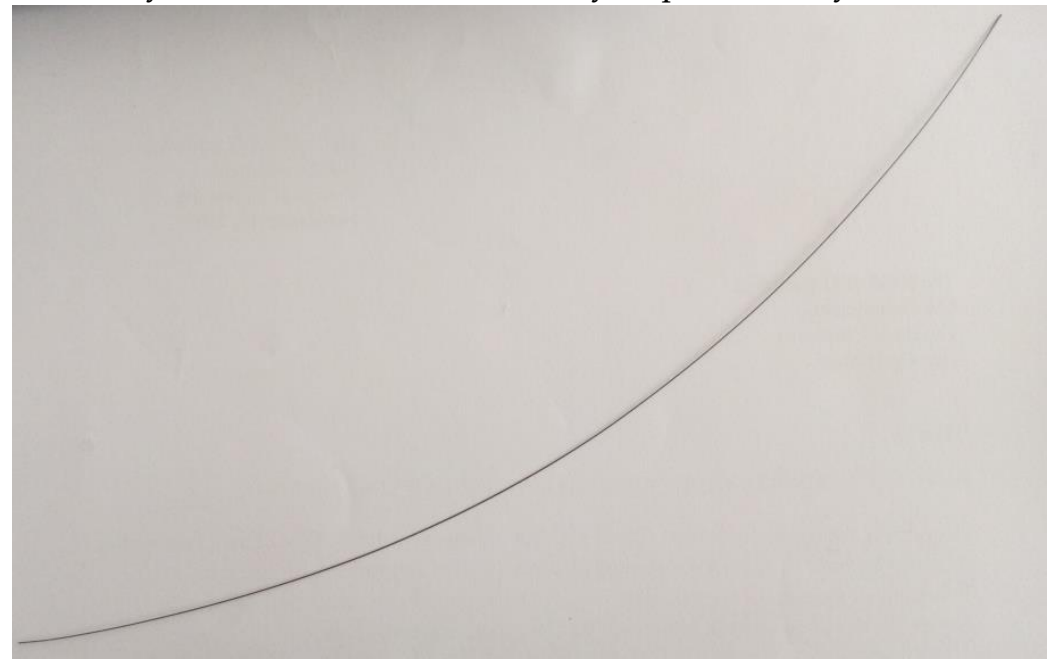

(a)

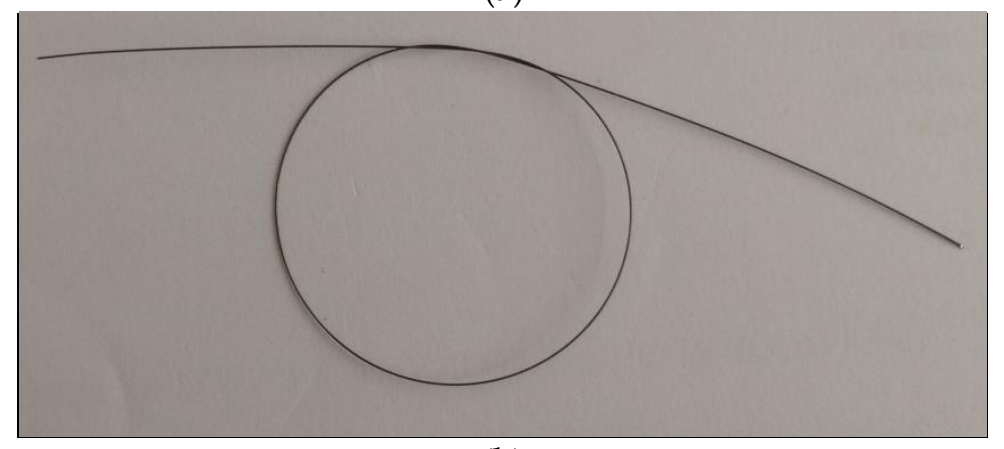

(b)

Figure 6. (a) A superelastic alloy in Form A at low temperature, it is not subjected to any external force; (b) A superelastic alloy in Form B at low temperature, it is subjected to an external force that is imposed by the knot, when the external force is removed, it springs back to Form A (Fig 6b).

\section{Results}

This section.

\subsection{Open-Loop Nitinol Wire Control Circuit}

SMAs are applied in this w ork as switching devices or electrical actuators. These are mechanical devices that create a movement when an electrical current is passed. Their advantage over traditional designs is that they have no moving parts other than those to which the smart alloy is attached. In addition to their use in robotics, other examples include the central locking system in cars, retractable headlamps, valves for controlling air flow, fast-acting fuses to protect against lightening, wing flaps on aeroplanes, and the barriers and signals in model train sets

In open loop control, there is no feedback. The supply voltage is simply switched on or off - for example, using a press switch or a timer circuit. Switches that can be used include reed switches operated by a magnet, micro switches or membrane panels. Supply current can be 'switched' by a thyristor, bipolar transistor or FET (field effect transistor). The control circuit shows how the piezoelectric sensor can control the supply switching. A bipolar transistor is used as the output stage of microelectronic control circuit. 


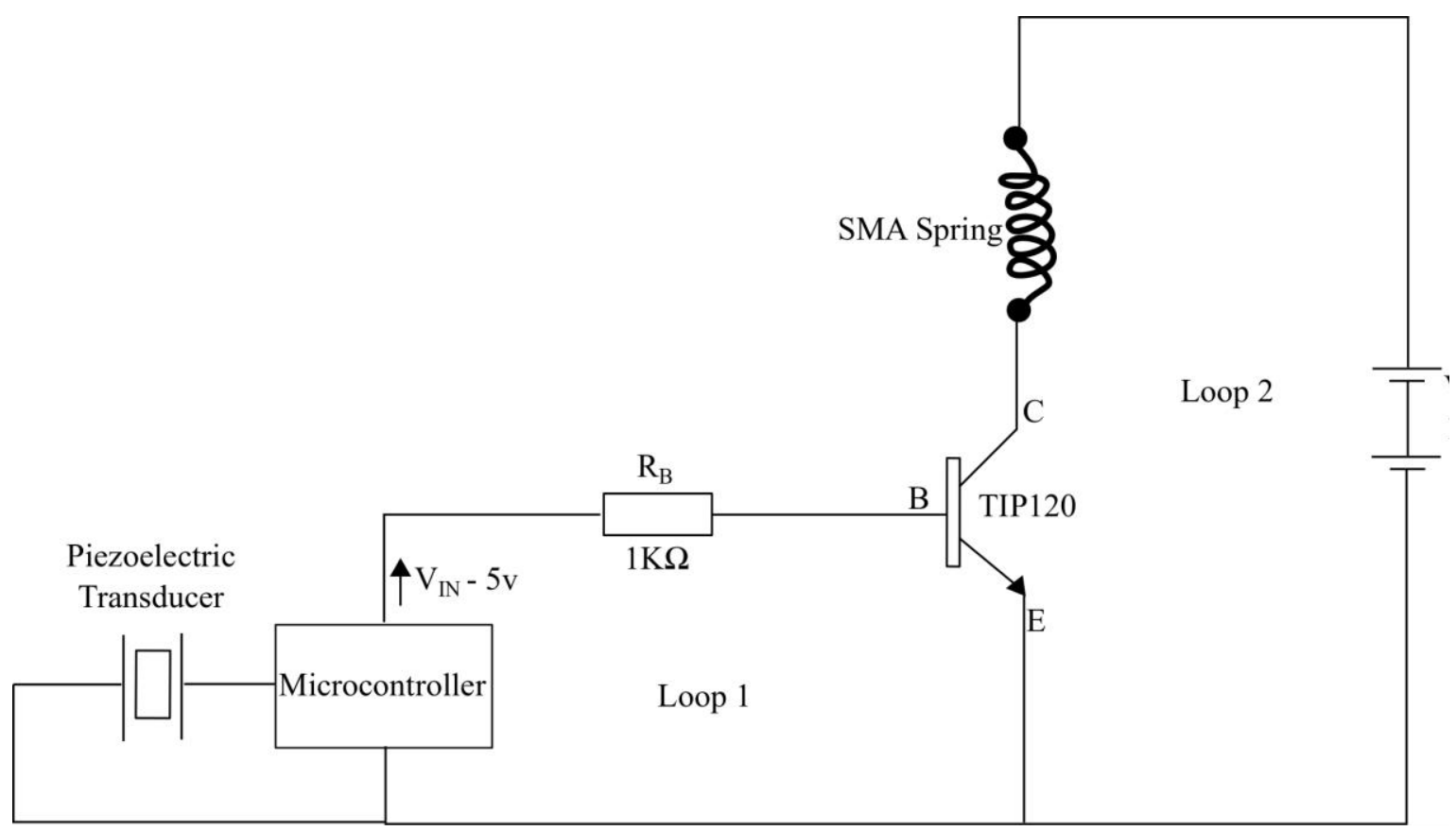

Figure 7. Schematic Circuit for the Shock-Triggered Open-Loop Control of SMA controlled by transistor and a microcontroller with a pie zo transducer as the input.

Figure 7 shows a schematic circuit to implement the Shock-Triggered Open-Loop Control of SMA using a transistor arrangement. $V_{I N}$ is the control voltage used to determine if the transistor is $\mathrm{OFF}$ or $\mathrm{ON}$. When the transistor is $\mathrm{ON}$, current flows around loop 2 from $C$ to $E$. When the Bipolar Junction Transistor (BJT) is OFF, no current flows through loop 2. $R_{B}$ limits the base current into the transistor. To analyse the loop from $V_{I N}$ to $R_{B}$ and across the $B E$ junction, if the PN junction is forw ard biased, $V_{I N}$ is greater than $0.65 \mathrm{~V}$ or $0.7 \mathrm{~V}$. Current will flow into the base of the transistor around this loop. For a BJT in its active region, $I_{C}=I_{B}$. If $V_{I N}$ is large enough to forward bias this junction to cause base current to flow, then collector current flows in to the transistor and turns $\mathrm{ON}$ so current flows around loop 1. If $V_{I N}$ is small, then $V_{B E}$ is small, the transistor is OFF and no $I_{C}$ flows, $I_{C}=0$. But if $V_{I N}$ is large enough, then $I_{C}$ is non-zero and the transistor turns ON. When $V_{I N}=0$, the transistor is in its cut off region and the voltage $V_{c e}$ equals $12 \mathrm{~V}$. As $V_{I N}$ increases, $I_{B}$ likewise increases so the cut off region is moved out of.

$V_{I N}$ can be designed to be an output connected to an embedded controller, this output pin generates a voltage betw een HIGH $(5 \mathrm{~V})$ and LOW $(0 \mathrm{~V})$. A HIGH voltage causes the transistor to turn ON which will cause current to flow in loop 2, so a connected actuator such as a SMA will be energized. If a LOW voltage, $V_{I N}=0 V$, is w ritten, the transistor will be OFF so the actuator will be OFF. A varying voltage at $V_{I N}$ will cause the same corresponding effect at the actuator. In this configuration, the transistor acts as an amplifier so that a small current from the controller results in a large current that drives the actuator. By w riting varying values in the range of HIGH to LOW into the $V_{I N}$, the duty cycle of the voltage into the SMA is varied at a fixed frequency.

The piezoelectric transducer is used for the shock-triggered open-loop control. When the piezo is triggered by tapping or shock, a control algorithm implemented in the microcontroller produces a $V_{I N}=5 \mathrm{~V}$, which would contract the SMA spring. When the piezo is left untriggered, a $V_{I N}=0 \mathrm{~V}$ is produced which de-energizes the spring.

\subsection{Electrical Actuation of a Model Robotic Arm with Shape Memory Springs}

The shape memory effect is applied to a model of a robotic arm. The model uses two pieces of Shape Memory Springs connected to a lever on either side of a pivot. When a voltage is connected to one of the smart wires, the spring contracts (by about 5\%) and the lever moves. If the voltage is 
disconnected, and current is now passed through the other spring, the lever moves back in the opposite direction.

In the robot arm model application in this w ork, a restoring force is provided by the contraction of the other wire when heated. The restoring force can also be applied by stretching the contracted wire to its original length and moving the robot arm.

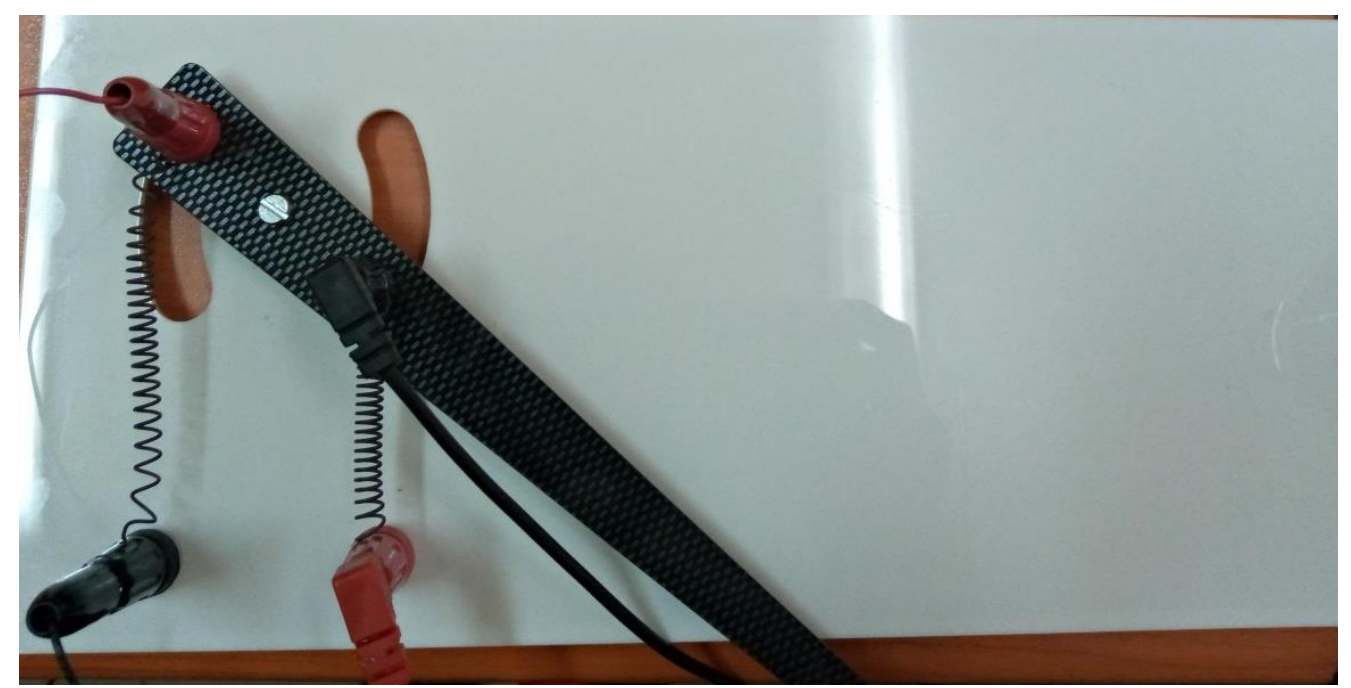

(a)

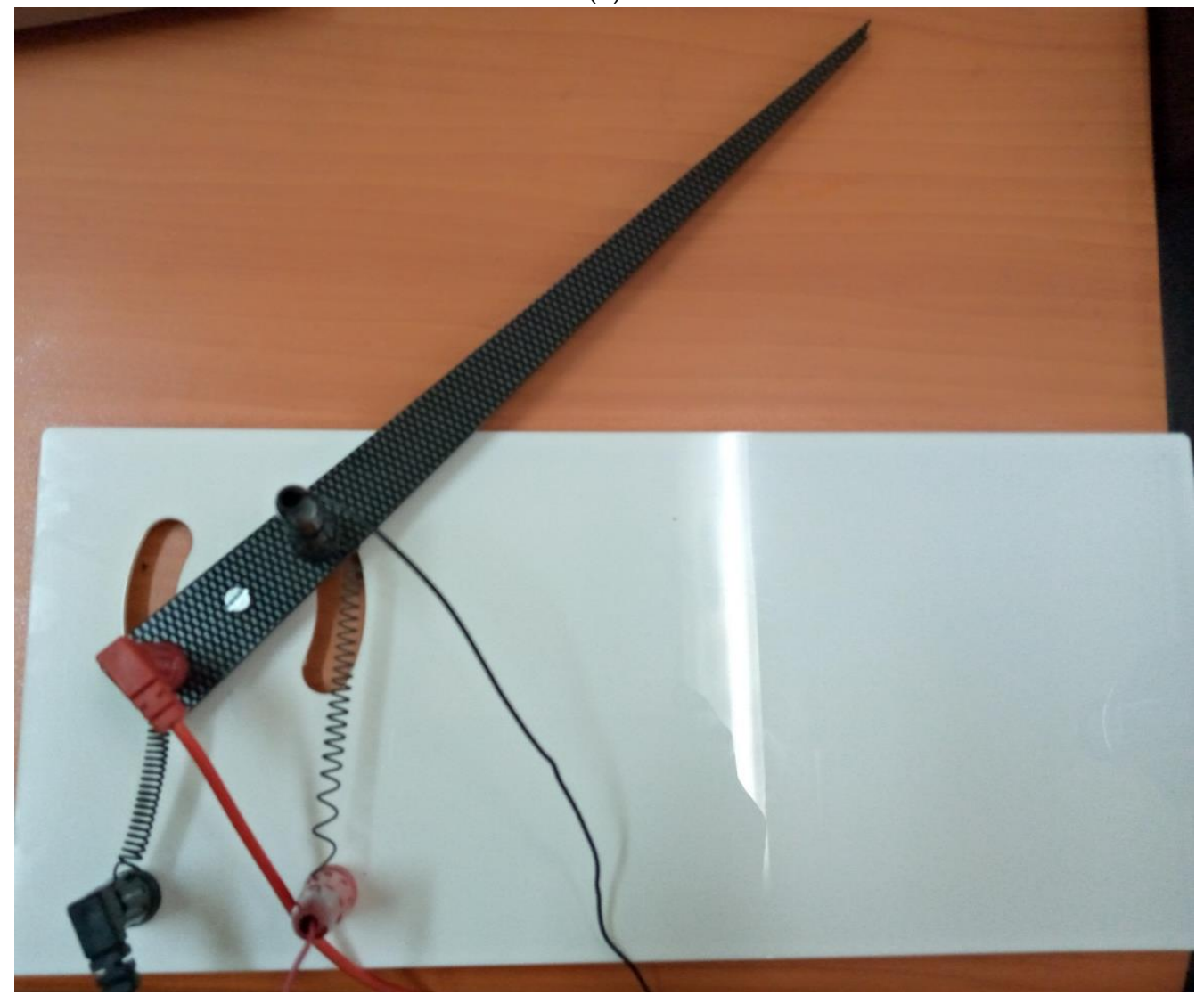

(b)

Figure 8. (a) A model of a robot arm indicating an electrical current controlling the lengths of the smart wires to move the lever arm downwards when SMA Spring 1 is relaxed and SMA Spring 2 is heated; (b) A model of a robot arm indica ting an electrical current controlling the lengths of the smart wires to move the leverarm upwards when SMA Spring 2 is relaxed and SMASpring 1 is heated.

\section{Discussion}


The bidirectional movement of a robotic lever through Shape Memory Spring Actuation via a microelectronic circuit through tapping movements on a piezo transducer has been designed. SMAs, also called smart alloys can be made with different transition temperatures, and the change in shape of these materials (shape memory springs and wires, two-w ay shape memory alloys, shape memory polymers and superelastic alloys) when they are heated or cooled can be used in a wide variety of applications which is not only limited to thermal actuators but for free recovery and constrained recovery applications. For example, SMAs are programmed into kettles, so that when water starts boiling, the heat makes the alloy change shape and switch off the current. Other examples are thermostats in a central heating system, a device for programming the opening and closing of windows according to temperature change, and in a tap to control the proportions of hot and cold water. In free recovery applications, SMAs can be used as blood clot filters, and in the construction of solar panels. In constrained recovery applications, they can be used to make bone plates that hold broken bones in place during healing.

\section{Conclusions}

The demonstration of a shock-triggered open-loop control of SMA spring has been implemented. The different types of Shape Memory Alloys and Polymers have been discussed together with their actuation techniques and applications/ SMA springs have been applied in this work to move a lever arm of a robotic joint. Owing to the large amount of current and high temperatures needed to cause electrical actuation of SMA materials, they are not well suited in wearable robotics applications but find other applications in humanoid robot design and electrothermal actuators.

Conflicts of Interest: “The author declare no conflict of interest."

\section{References}

1. Andreasen, G. F., \& Morrow, R. E. (1978). Laboratory and clinical analyses of nitinol wire. Ame rican journal of orthodontics, 73(2), 142-151.

2. Otsuka, K., \& Wayman, C. M. (Eds.). (1999). Shape memory materials. Cambridge unive rsity press.

3. Xie, T. (2010). Tunable polymer multi-shape memory effect. Nature, 464(7286), 267-270.

4. Tanaka, K., Kobayashi, S., \& Sato, Y. (1986). Thermomechanics of transformation pseudoelasticity and shape memory effect in alloys. International Journal of Plasticity, 2(1), 59-72.

5. Sato, A., Chishima, E., Soma, K., \& Mori, T. (1982). Sha pe memory effect in $\gamma \rightleftarrows €$ transformation in Fe-30Mn1Si alloy single crystals. Acta Metallurgica, 30(6), 1177-1183.

6. Sato, A., Chishima, E., Soma, K., \& Mori, T. (1982). Shape memory effect in $\gamma \rightleftarrows \epsilon$ transformation in Fe-30Mn1Si alloy single crystals. Acta Metallurgica, 30(6), 1177-1183.

7. Jang, J. H., Koh, C. Y., Bertoldi, K., Boyce, M. C., \& Thomas, E. L. (2009). Combining pattern instability and shape-memory hysteresis for phononic switching. Nano letters, 9(5), 2113-2119.

8. Liu, Y., Liu, Y., \& Van Humbeeck, J. (1998). Two-way shape memory effect developed by martensite deformation in NiTi. Acta materialia, 47(1), 199-209.

9. McClung, A. J., Tandon, G. P., \& Baur, J. W. (2012). Strain rate-and temperature-dependent tensile properties of an epoxy-based, thermosetting, shape memory polymer (Veriflex-E). Mechanics of TimeDe pendent Materials, 16(2), 205-221.

10. Havens, E., Snyder, E. A., \& Tong, T. H. (2005, May). Light-activated shape memory polymers and associated applications. In Smart Structures and Materials 2005: Industrial and Commercial Applications of Smart Structures Technologies (Vol.5762, pp. 48-55). International Society for Optics and Photonics.

11. DesRoches, R., McCormick, J., \& Delemont, M. (2004). Cyclic propertie s of superelastic shape memory alloy wires and bars. Journal of Structural Engineering, 130(1), 38-46.

12. Brailovski, V., \& Trochu, F. (1996). Review of shape memory alloys medical applications in Russia. Biomedical materials and engineering, 6(4), 291-298.

13. Machado, L. G., \& Savi, M. A. (2003). Medical applications of shape memory alloys. Brazilian journal of medical and biological re search, 36(6), 683-691. 
14. Cragg, A., Lund, G., Rysavy, J., Castaneda, F., Castaneda-Zuniga, W., \& Amplatz, K. (1983). Nonsurgical placement of arterial endoprostheses: a new technique using nitinol wire. Radiology, 147(1), 261-263. https://doi.org/10.1148/radiology.147.1.6828742

15. Huang, X., \& Liu, Y. (2001). Effect of annealing on the transformation behavior and supe relasticity of NiTi shape memory alloy. Scripta Ma terialia, 45(2), 153-160.

(C) 2020 by the authors; licensee MDPI, Basel, Switzerland. This article is an open access article distribute $\mathrm{d}$ under the terms and conditions of the Creative Commons by Attribution (CC-BY) license (http://creativecommons.org/licenses/by/4.0/). 